This article has been scanned by iThenticat No plagiarism detected

Volume 3, Issue 5, October 2021

p. 406-415

\title{
NUMERAL FINANCE IN ISLAMIC JURISPRUDENCE
}

http://dx.doi.org/10.47832/2757-5403.5-3.34

\section{Hanaa Mohammed Hossein Ahamed AL-TAMMIMY1}

\begin{abstract}
:
The purposes of Islamic Shari are to bring utilities and benefits and also to avoid depravation.This sharia is very suitable for human instinct ; it is valid for every place and time.

Our respectable jurists said that non of difficulties hasn't a rule in our god's book so we have to be aware of the rules and judgments' of those troubles and what is expected to happen.

In this research, in God's willing, we declare the jurisprudent regionalization (adaptation) of electronic digital money (system of transferring electronic money) and what is related to this system of jurisprudent restrains because the electronic money is people's needs which contributes in accomplish their finance dealings by great quickness to transfer their money with reducing its expenses that the finance dealing is considered as a practical life nerve that pours in individual's controlled benefits which doesn't contradict with Islamic sharia goals and principles.

So, it is important to know the jurisprudent terms and to evaluate economic and banking work that is included in principles of Islamic sharia, according to jurisprudent rules connected with Islamic banks work.
\end{abstract} Received: 20/08/2021

Key words: The purposes of Islamic Shari, Islamic jurisprudence, Numeral Finance.

\footnotetext{
${ }^{1}$ Dr., Baghdad University, Iraq, hana72na@yahoo.com, https://orcid.org/0000-0003-3609-0987
}

Copyright $\odot$ Published by IJHER Journal, www.ijherjournal.com Rimar Academy, Fatih, Istanbul, 34093 Turkey

All rights reserved 


\title{
التمويل الرقمي في الفقه الإسلامي
}

\section{هناء محمد حسين احمد التميمي 2}

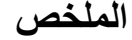

إن أهم مقصد من مقاصد الثريعة الإسلامية هي جلب المنافع ودرء المفاسد، كونها شريعة

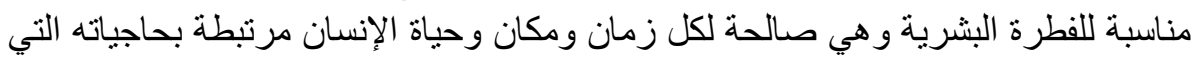

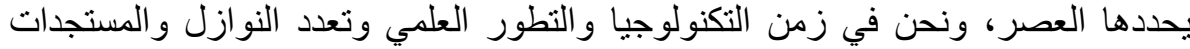

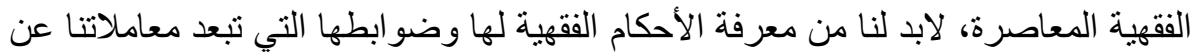

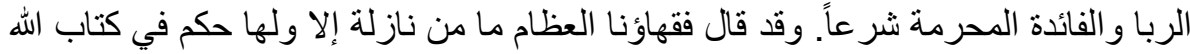

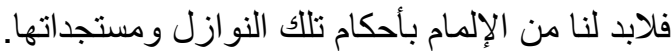

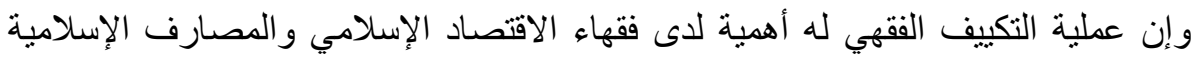

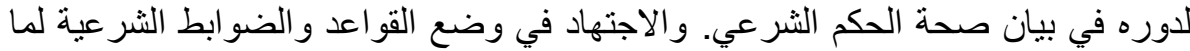

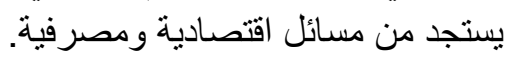
وفي هذا البحث نبين التأصيل (التكييف) الفقهي للنقود الرقمية، وما يتعلق بها من ضوابط التهائ فقهية، كون النقود بكل صورها تمثل حاجة من حاجيات الناس التي تُسهم في انجاز

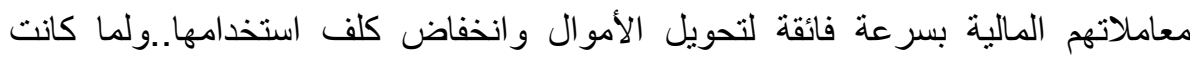
المعاملات المالية هي عصب الحياة العملية للفرد، وللمجتمع، وتنصب في في مصلحته المانه المنضبطة التي لا تتعارض هي ومقاصد الثريعة الإسلامية ومبادئها.

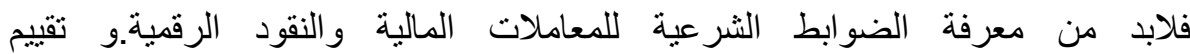

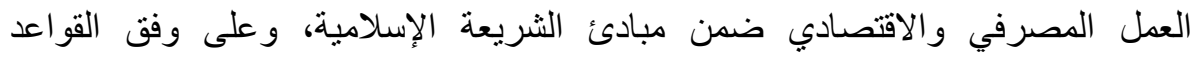
الفقية المتعلقة بعمل المصارف الإسلامية. وبيان التكييف الفقهي لهكذا معاملات مالية معاصرة. الكلمات المفتاحية: التمويل الرقمي، الفقه الإسلامي، مقاصد الثريعة.
\end{abstract}

إن التشريع الإسلامي وما يتميز به من شمول ومرونة وو اقعية يستو عب المستجدات كافة بنصوصه الثر عية والاجتهادات

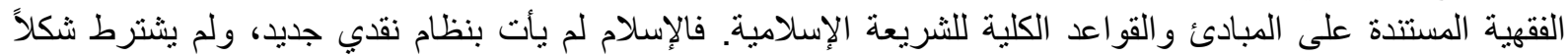
معيناً للنقود، بل ترك ذلك لعرف الناس، لكنه ضبط دور النقود في أحكام خاصة لتؤدي دور ها الاقتصادي بكفاءة، كونها أداة لتحقيق وظائف معينة. فكفاءة النقود في النظام الإسلامي لا تتطلب شكلاً معيناً، وإنما ترد كفاءتها إلى أداء وظائفها بشكل كامل، فيقول حجة التهائ

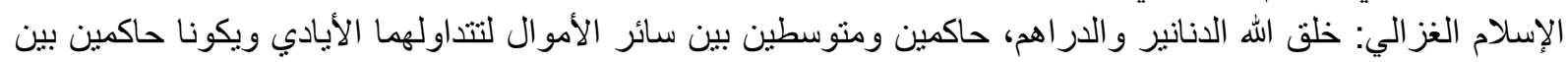

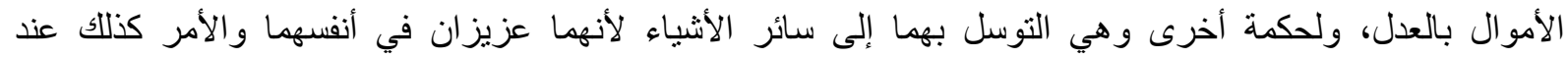

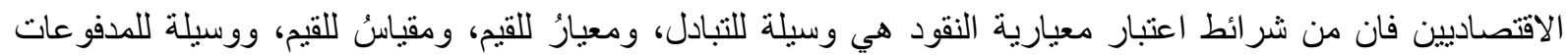
الآجلة.

ومن القضايا المعاصرة هي تطور النظام النقدي الرقمي المالي والحصول على وسيط ثقة يجعل المعاملات المالية

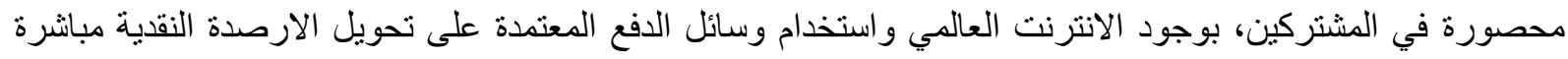

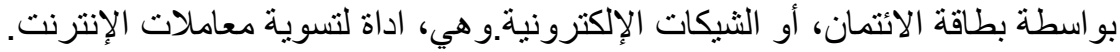

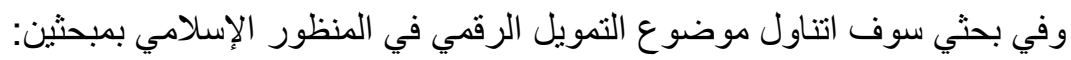
الأول: يضم سمات النظام الاقتصادي الإسلامي، والمصارف الإسلامية، المصارف الرقمية الإسلامية، النقود الرقمية و التكييف الفقهي الثرعي لها. 
الثاني: يضم الضو ابط الثرعية للمعاملات المالية المصرفية العملة الرقمية اهمية التمويل الرقمي.

المطلب الأول: سمات النظام الاقتصادي الإسلامي

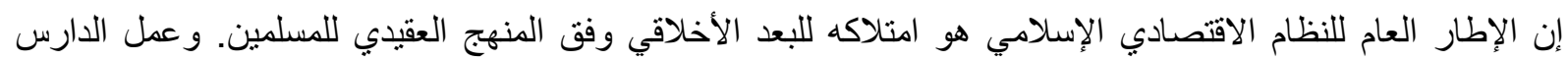

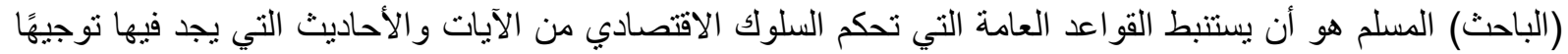

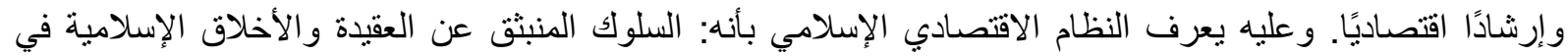

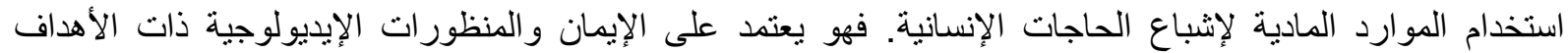
الأخلاقية والنفسية و العبودية. ويهدف إلى الابتعاد عن المادية المفرطة والاستغلال كونه عقيدة اقتصادية متكاملة وليست

اقتصادية علمية.

فهو اقتصاد رباني، و عقدي، و أخلاقي، وو اقعي، و إنساني عالمي، يو ازن بين مصلحة الفرد و المجتمع، فلا يحرم و لا يبيح

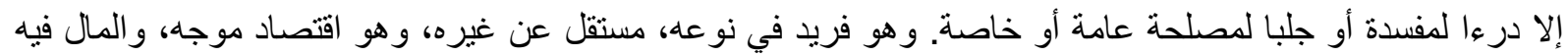

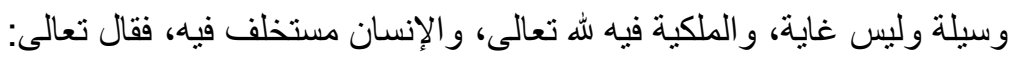

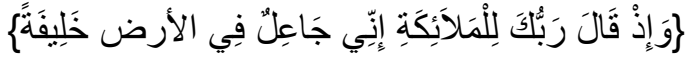

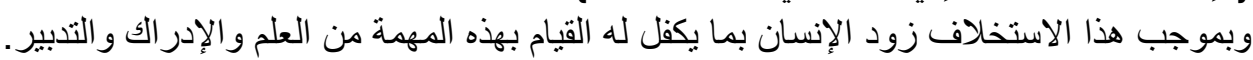

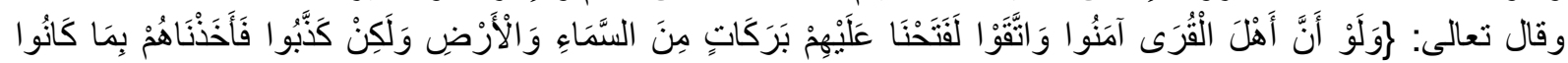

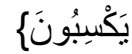

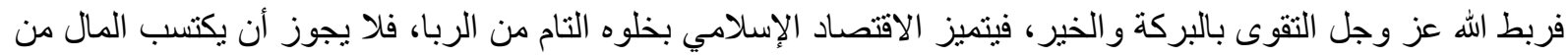

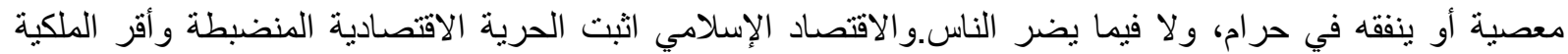

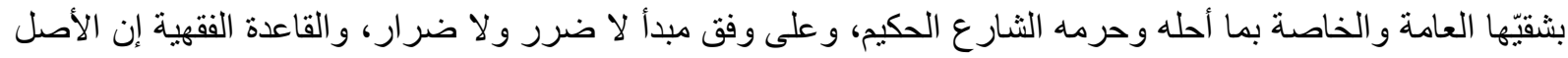
في المعاملات الإباحة.

المطلب الثاني: المصارف الإسلامية:

الأصل في المصارف الإسلامية أنها ملتزمة في معاملاتها بأحكام ومبادئ الشريعة الإسلامية، وأهمها أن لا تتعامل بالربا

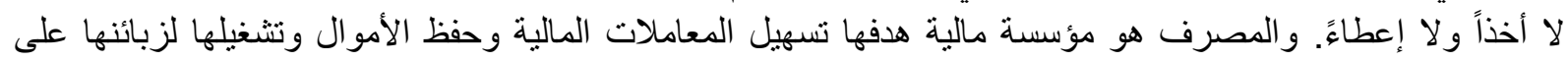

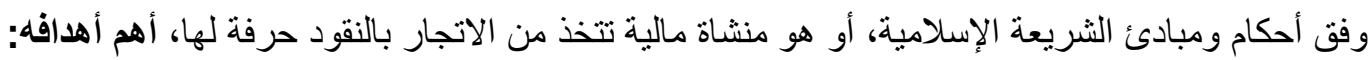

ـ تقديم الخدمات المصرفية وممارسة أعمال التمويل والاستثمار القائمة على أساس الفائدة غير الربوية في جميع صور ها

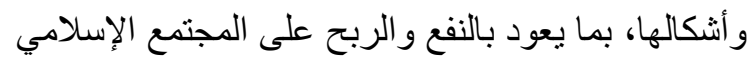

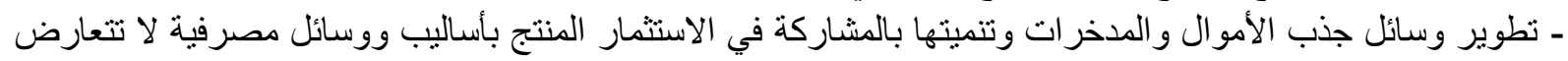

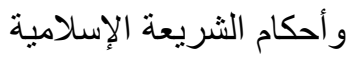
ـ تحقيق المنهج الإسلامي في المعاملات المالية للمساهمة بالتتمية الاقتصادية و الاجتماعية الثاملة للمجتمع. - توفير الأمان في توظيف أمو ال المودعين و المستثمرين و المساهمين لتعظيمها وتتميتها.

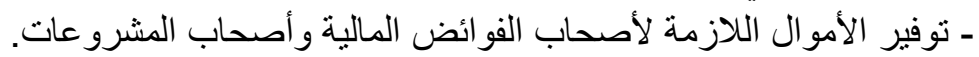

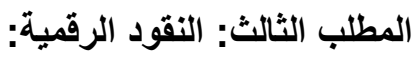

المصارف الإسلامية يجب عليها ان تقوم بتطوير المنتجات المصرفية التي تقدمها لزبائنها بما لا يخالف أحكام الثريعة

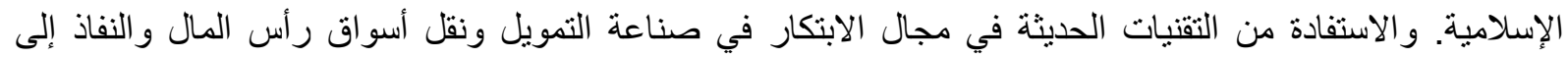
الأسواق العالمية واستغلال فرص التكنولوجيا المالية والثمول المالي الرقمي لتعزيز نطاق وصولها لإلها للمستخدمين و الاستفادة من شرائح جديدة للعملاء المستبعدين ماليا من النظام المصرفي، ويمكن لها أن تستفبد من استخدام مختلف

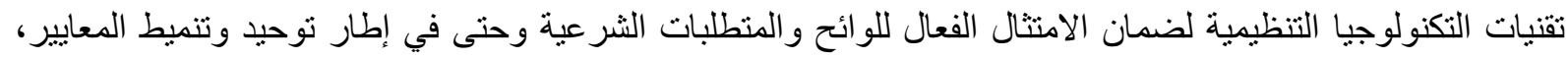
مما يعزز من نمو الصناعة ويقلل من مخاطر السمعة المتعلقة باحتمال خرق منطلبات الثريعة. 
و النقود بوجه عام: كل شيء يلاقي قبو لا عاما بين الناس ويعد وسيطا للتبادل أو لإبراء الديون. ولكي تؤدي النقود وظائفها على وفق المنظور الاقتصاد الإسلامي يجب أن أن تكون:

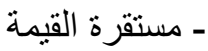

ـ ذات غطاء قانوني لها مدعم من الدولة المصدرة لها معلومة جهة الإصدار الضامنة و المالكة لها.

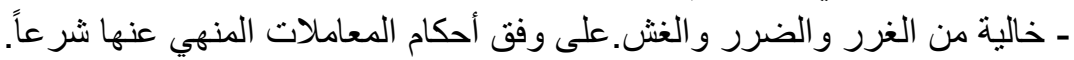

وللفقهاء في اطلاق كلمة النقود و استعمالاتها عدة ار اء ولكن بمكن القول بانها كل شىء بلقى قبو لاً عاماً كوسيط للتبادل

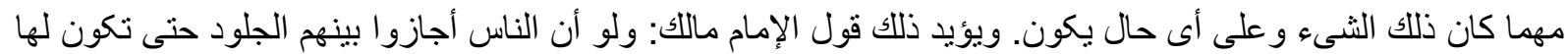

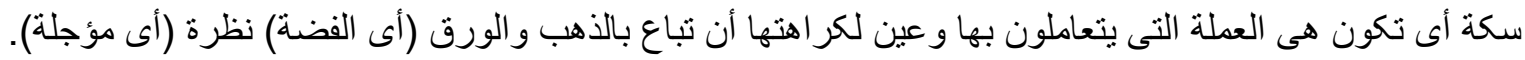

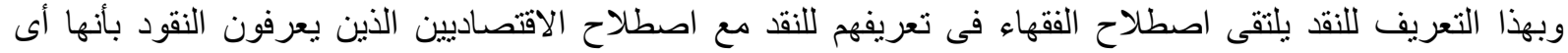

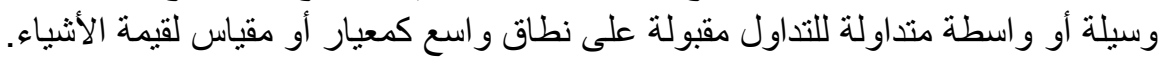

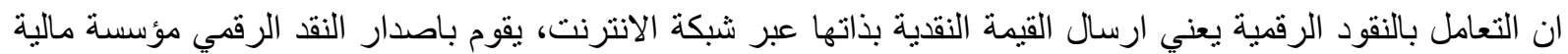

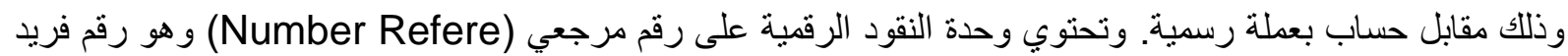

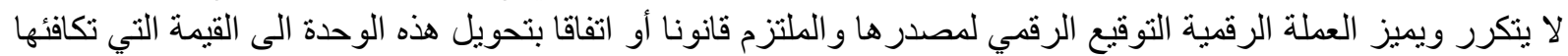

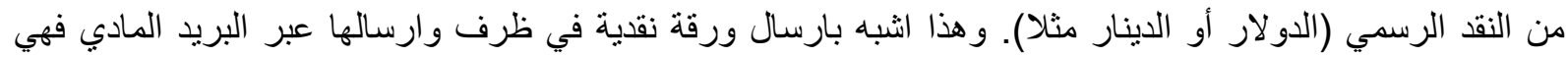

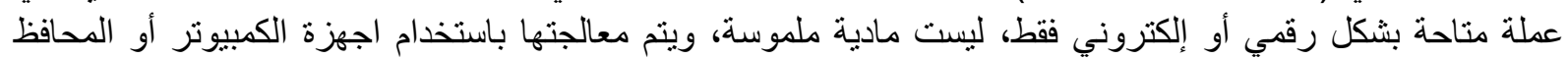

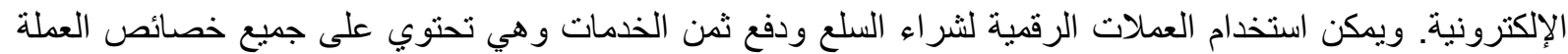

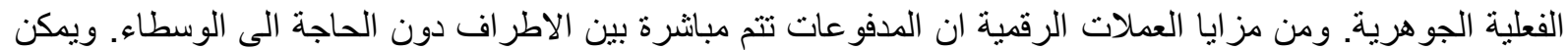

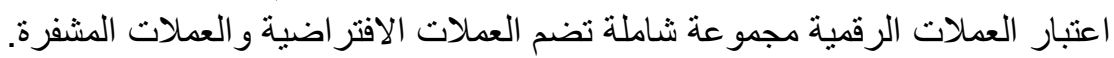

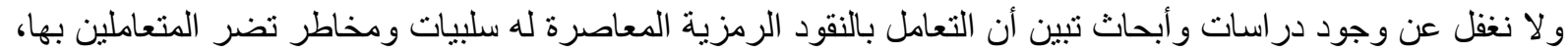

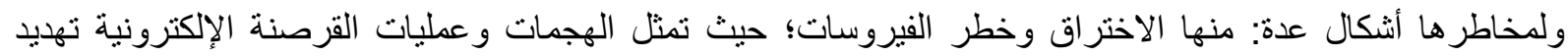

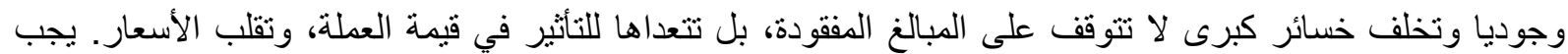

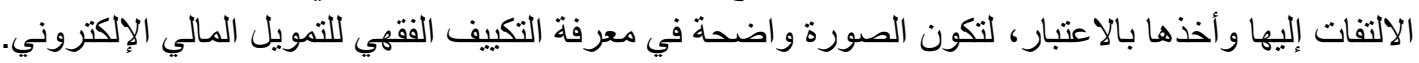

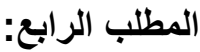

\section{التكييف الفقهي للنقود الرقمية:}

إن العصر الحالي يتطور حضاريا واجتماعيا يصاحبه تطور تكنولوجيا ينعكس هذا التطور على قضايا واقعه الاقتصادي،

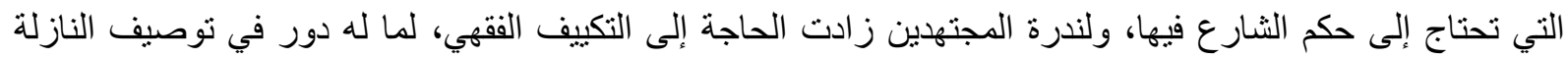
وتصورها وتحرير الأصل الذي تنتمي إليه وتقريب وجهات النظر حول الواقعة وتسهيل البحث فيها لعلماء التخريج

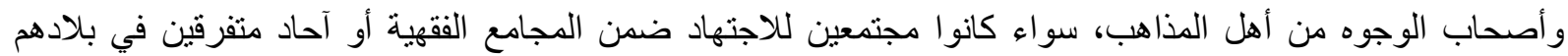
للإفتاء و التعليم.

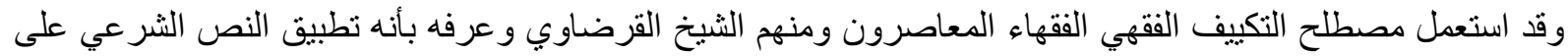

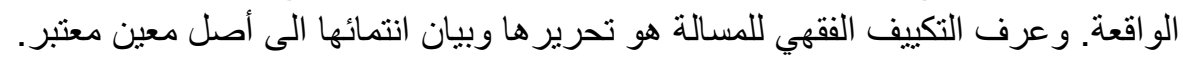

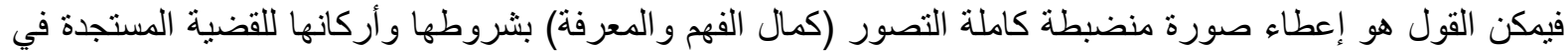

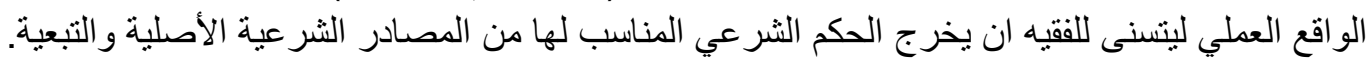
إذ إن التصور كما عرفة الإمام الجرجاني: حصول صورة الثيء في العقل، وإدراك الماهية من غير إن يحكم عليها بنفي

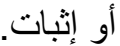
إما التخريج فمعناه الاستنباط وهو استنباط الأحكام الثرعية العملية من أدلتها التفصيلية على وفق القواعد الأصولية. أو ير اد به نقل حكم مسالة الى ما يشبهرها و التسوية بينهما فيه.

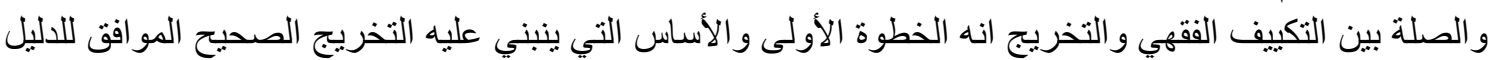

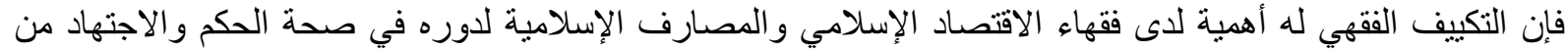

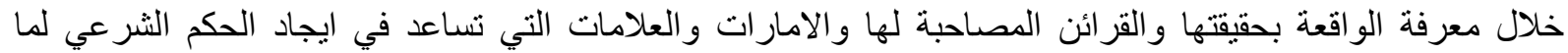
بستجد من مسائل مالية. 
ومن اجل التوصل الى حكم التعامل بالعملات الرقمية يجب البحث في طبيعتها وخصائصها.ومدى انطباقها مع عناصر

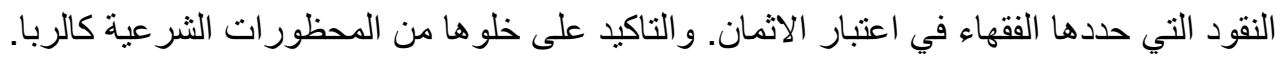

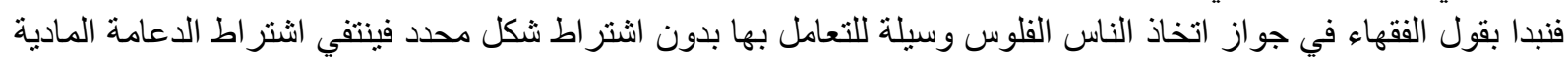

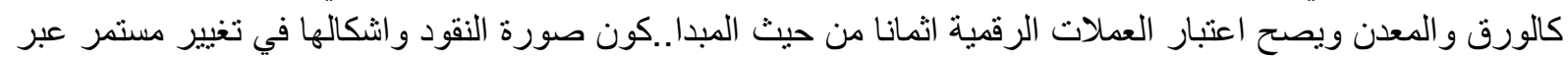

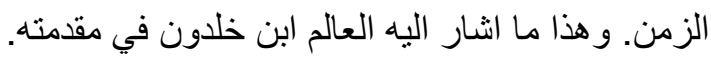

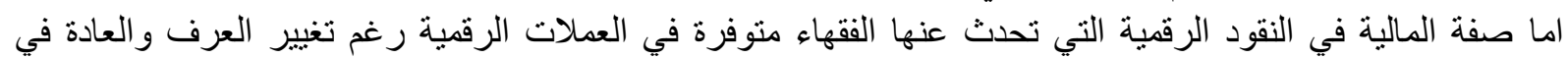

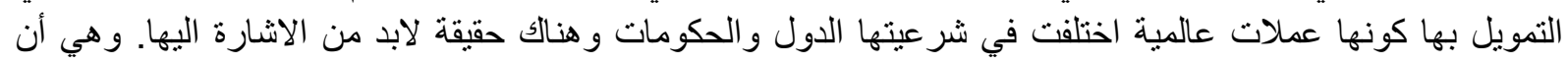

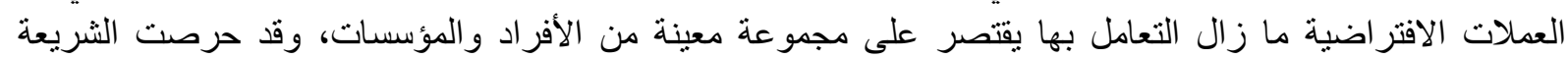

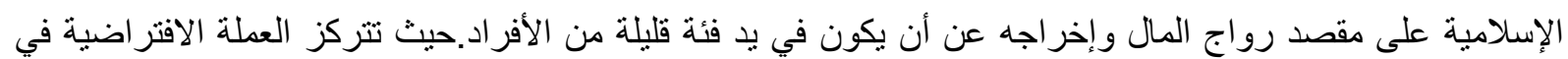

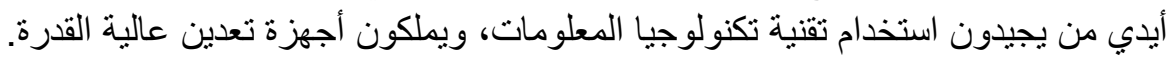

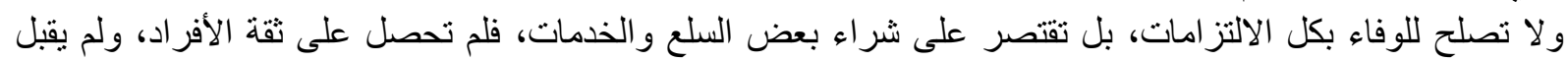

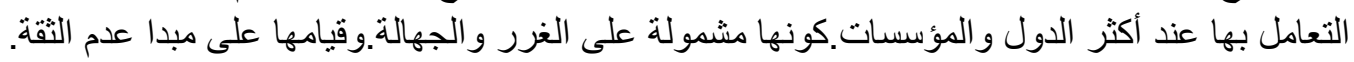

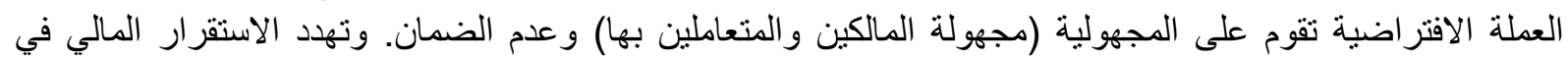

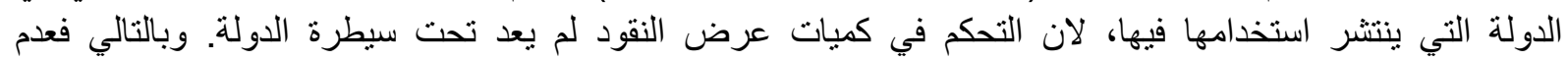
الاعتر اف بالعملات التشفيرية يجعل التعامل بها من المحظورات الثر عية. كونها نؤثر على اقتصاد الدولة. من حيث بيان

عائديتها.

المبحث الثاني:

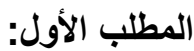

الضوابط الثرعية للمعاملات المالية المصرفية:

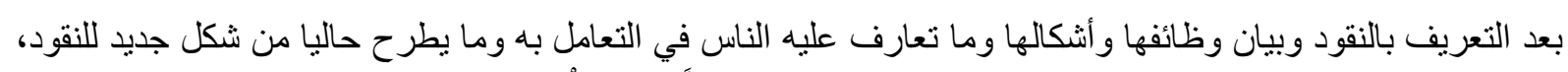

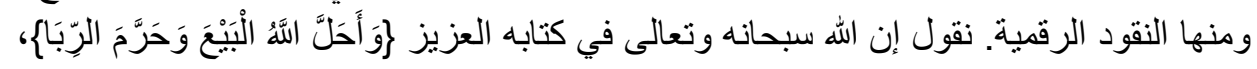

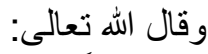

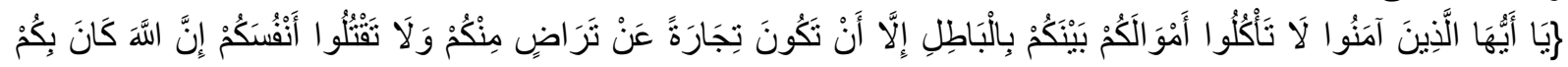

رَحِيمًا.

ولم يترك النص القرآني على إطلاقه بل قيدته السنة النبوية بتفاصيل وزادته توضيحاً استنباطات الفقهاء واجتهاداتهم

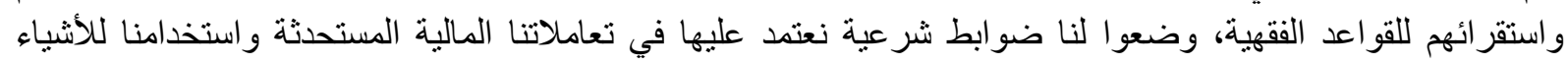
و واقيامها. و الضابط الثرعي هو الذي يبين شرعبة الحكم المستحدث والمعاصر منها، و على أساسها تحدد الأهداف والسياسات

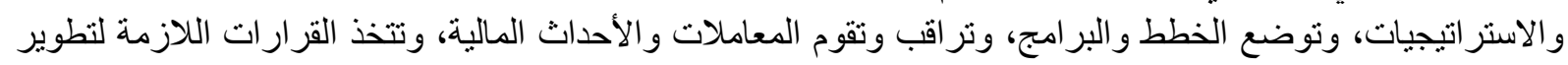

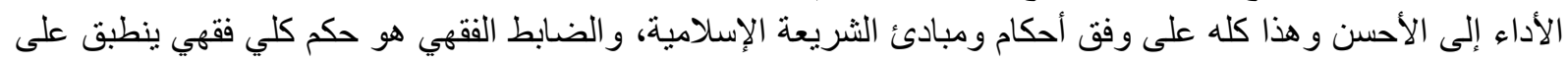

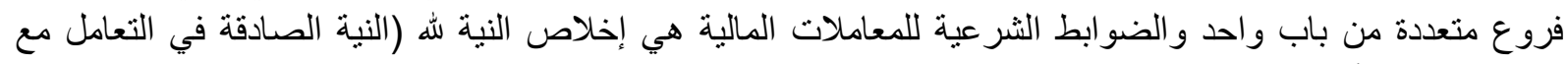

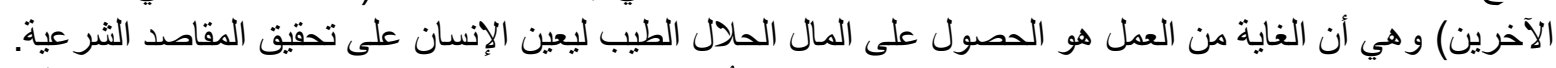

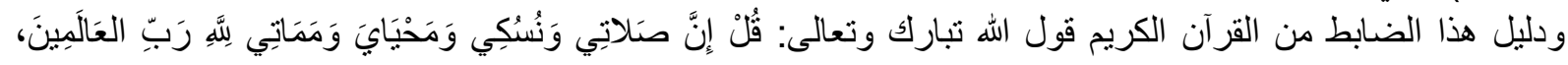

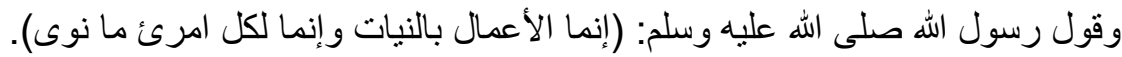

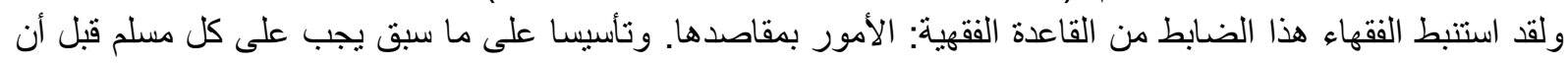

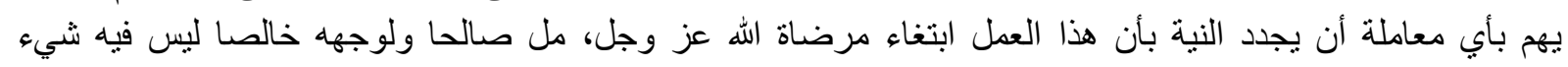
لهوى النفس.

المعاملات المصرفية تكون في مجال الطيبات، وتجنب الخبايث مهما كان قدرها:

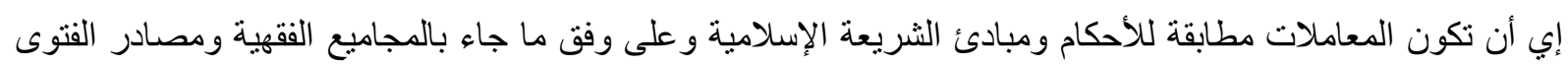

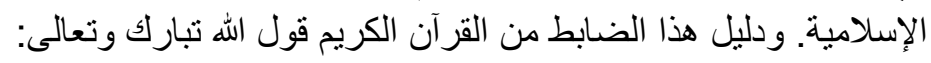




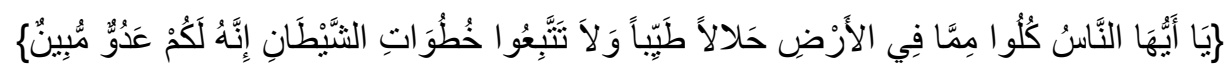
وقول رسول الله صلى الله عليه واله وسلم: (إن الله طيب لا يقبل إلا طيبا). و هذا الضابط مستتبط من القو اعد الفقهية الثر عية الآتية: ـ - الأصل في المعاملات الإباحة (الحل).

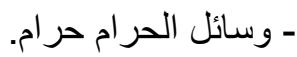
- ـ - من اختلط بماله الحلال حرام أخرج قدر الحرام والباقي حلال.

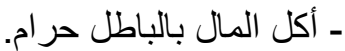

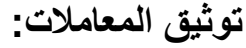

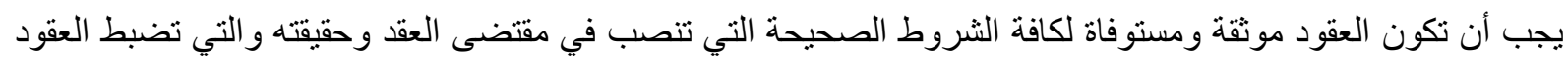

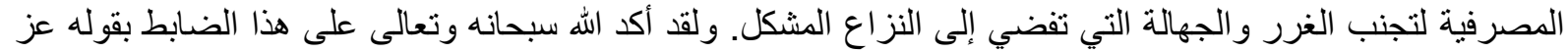
وجل:

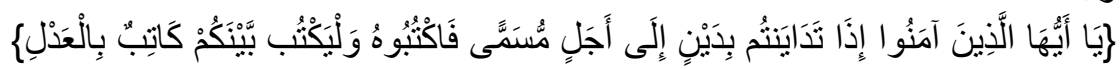

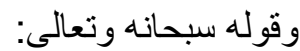

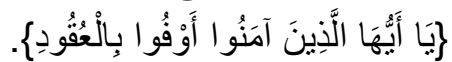
ويعود هذا الضابط للقاعدة الفقهية الأصل في العقود اللزوم.

خلو العقود المصرفية من (الغرر و الغش والجهالة والإذعان): إب أن تكون خالية من البيوع المنهي عنها شرعاً والتي تؤدي الى إبطالها أو فسادها، ولقد أكد القرآن على ذلك بقول الله

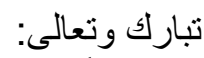

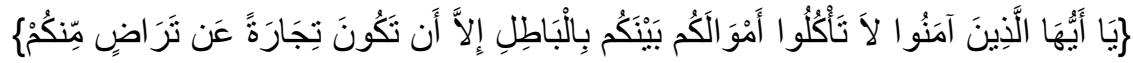

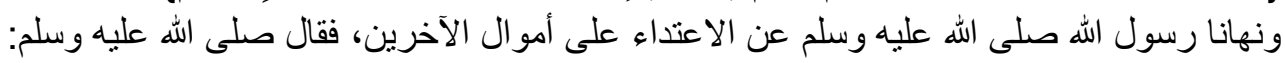

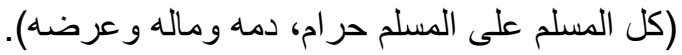
ومن القو اعد الفقهية التي تسند هذا الضابط:

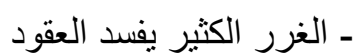

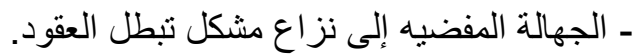

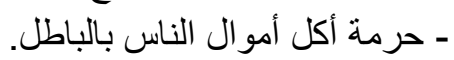

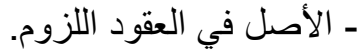

\section{مشروعية الغاية ومشروعية الوسيلة:}

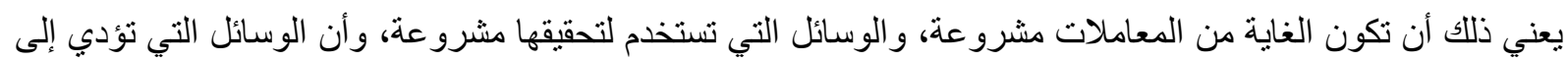

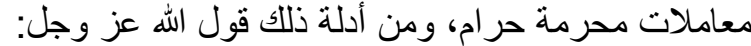

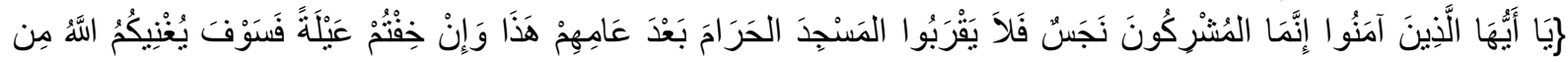

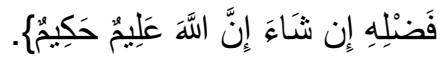
ويعود هذا الضابط إلى القو اعد الفقهية الآتية:

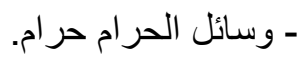

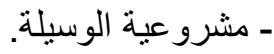

التيسير ورفع الحرج عن الناس:

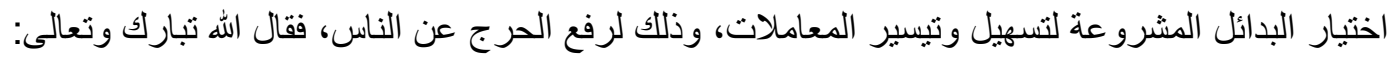

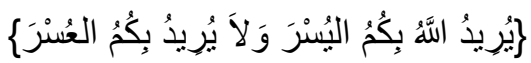




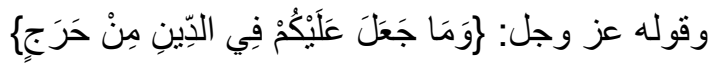

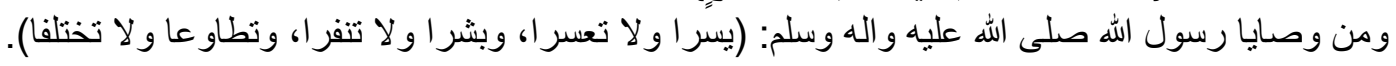
ويستند هذا الضابط إلى القو اعد الفقهية الثر عية الآتية:

$$
\begin{aligned}
& \text { ـ الضرور ات تبيح المحظور ات. } \\
& \text { ـ للأكثر حكم الكل، أو يأخذ اليسير حكم الكثير. } \\
& \text { ـ اليسير الحرام معفو عند في كثير من الأحوال. } \\
& \text { ـ ـ الغرر اليسير لا يفسد العقود. } \\
& \text { - المعروف عرفا كالمشروط شرطا. }
\end{aligned}
$$

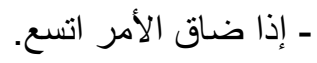

$$
\begin{aligned}
& \text { المحافظة على الأموال: - ال }
\end{aligned}
$$

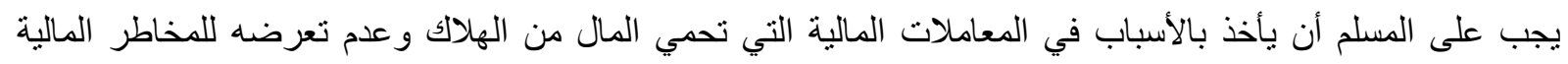

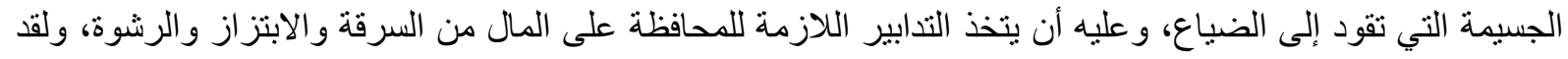

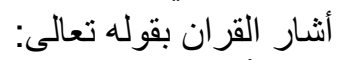

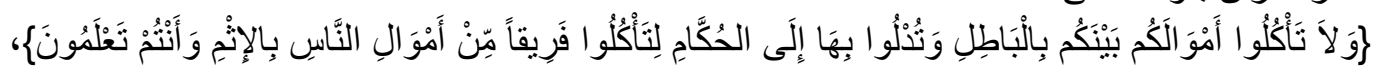

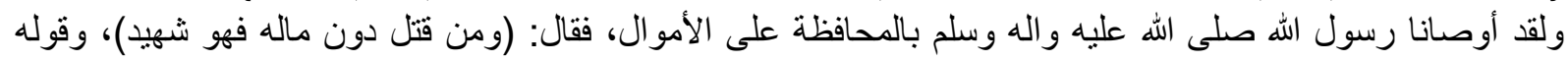

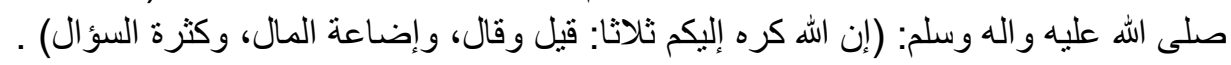
و القو اعد الفقهية الني تبين ذلك الضابط هي:

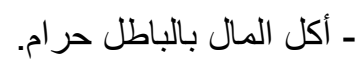

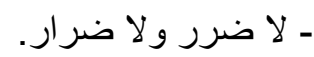

\section{حماية الملكية الفردية}

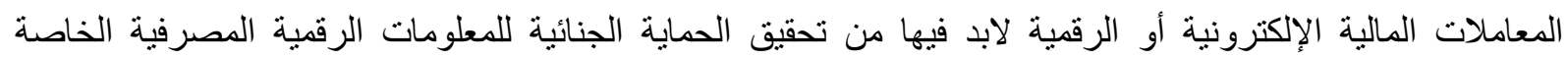

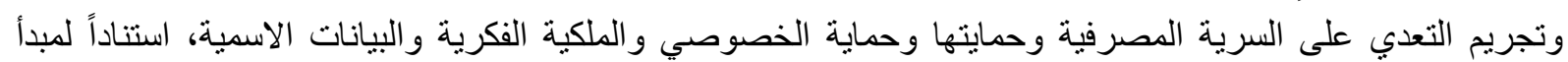

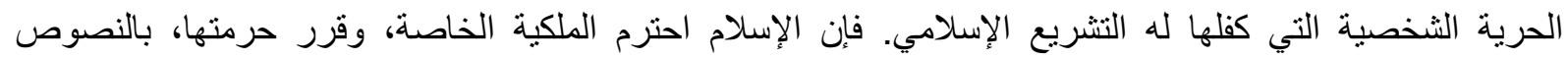

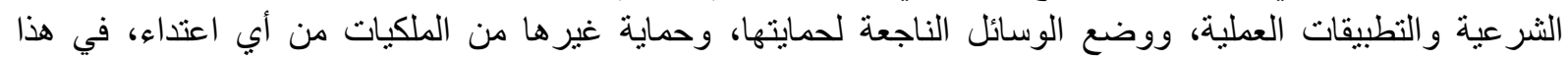

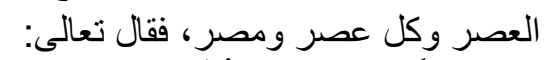

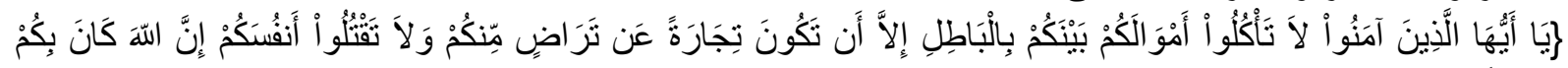
رَحِيماًُ

ومستند هذا الضابط القاعدة الفقهية:

ـ لو يعطى الناس بدعواهم، لادعى رجال أمو ال قوم ودماؤهم، لكن البينة على الددعي و اليمين على من أنكر.

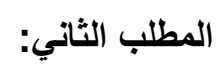

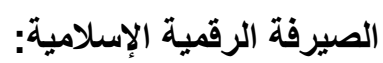

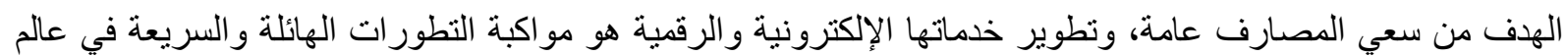

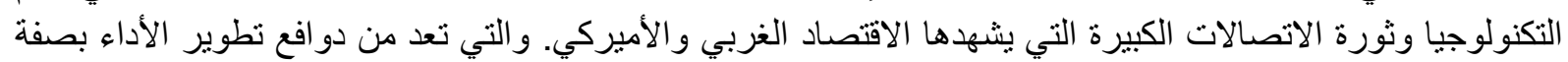

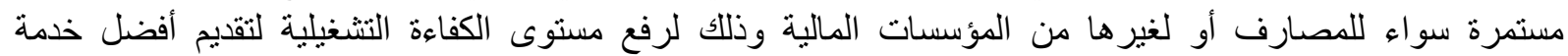

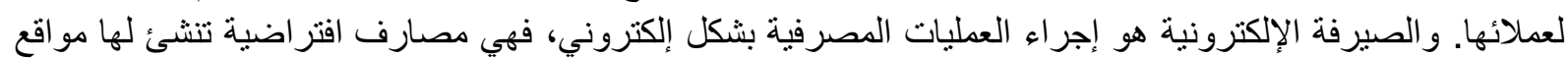

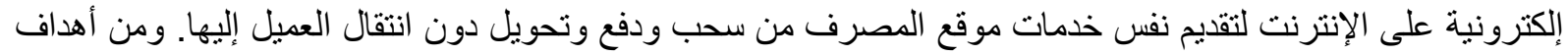

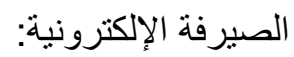
ـ - أنها تعد وسيلة لتعزيز حصنها في السوق المصرفية 
- خفض التكاليف و إتاحة المعلومات عن الخدمات التي يؤديها البنك دون تقديم خدمات مصرفية على شبكة الانترنت،

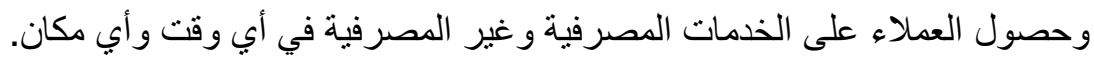

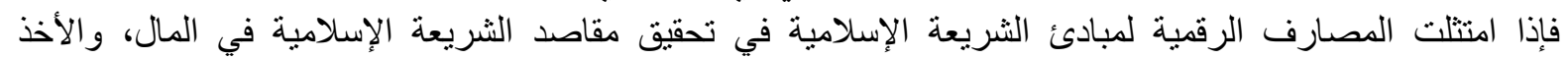

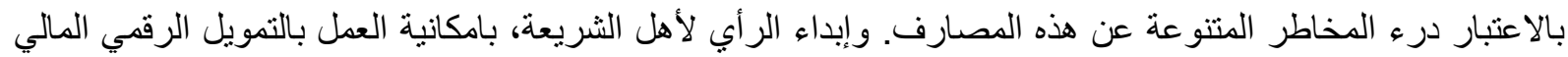

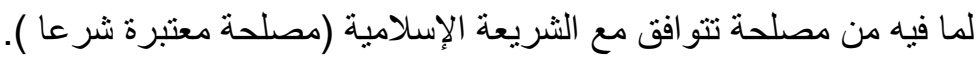

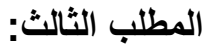 \\ أهمية التمويل الرقمي الإسلامي: - ألمي:}

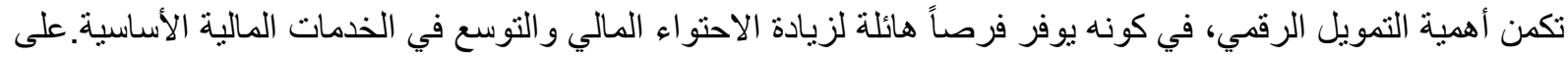

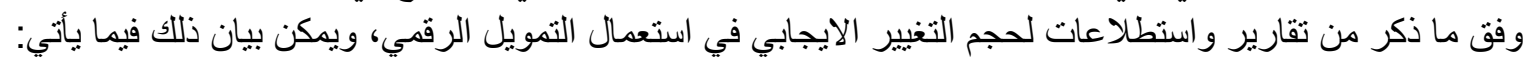
ـ يمثل وسيلة قوية لتوسيع نطاق الخدمات المالية إلى القطاعات الأخرى بما في ذلك الزر اعة و النقل و المياه و الصحة و التعليم و الطاقة النظيفة. - إن الحلول الرقمية و التكنولوجيا الجديدة توفر إمكانيات ضخمة للتغلب على التحديات الإنمائية الهائلة، و التي ستسهم في

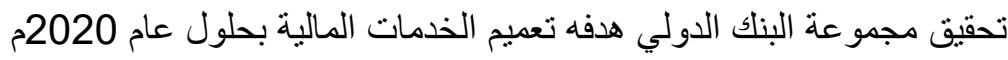

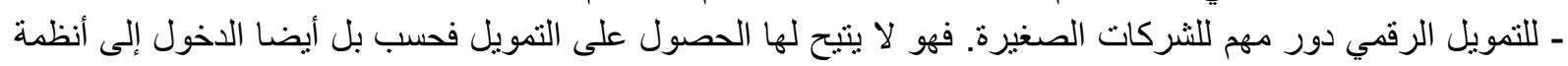

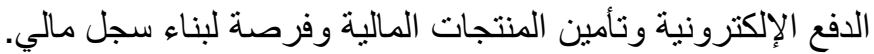

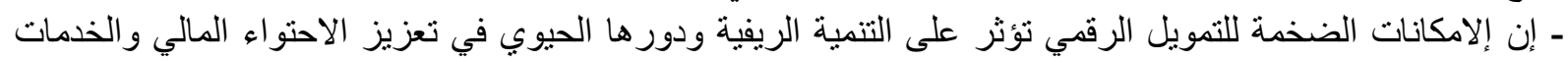

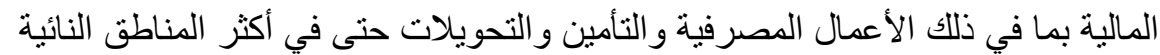

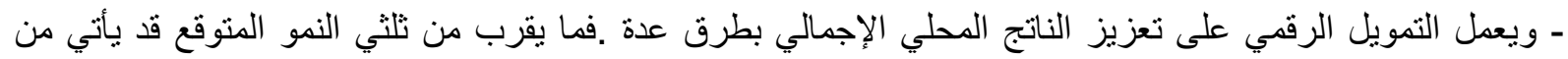

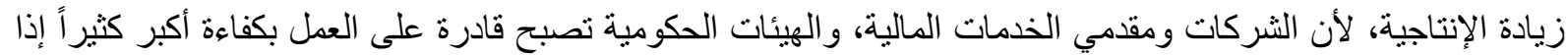

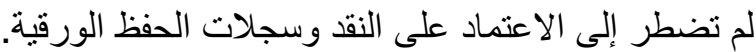

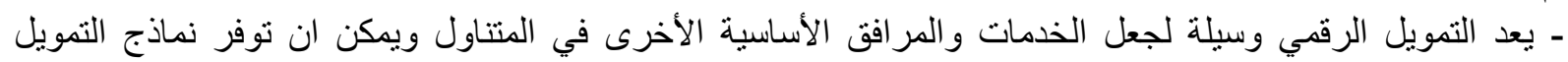

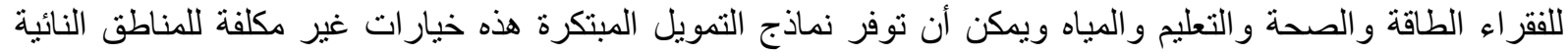

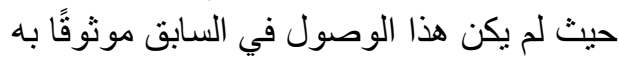

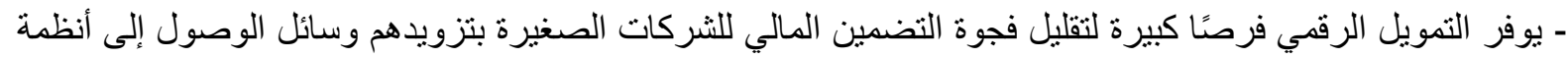

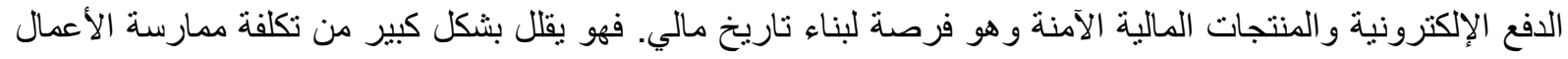
التجارية، وتثير الدراسات إلى أن المعاملات المصرفية عبر الهاتف المحمول يمكن أن تتم بنسبة 15٪ من كن تكلفة

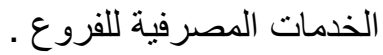

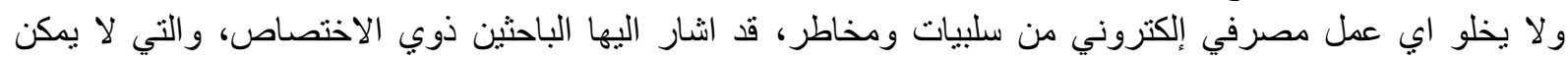

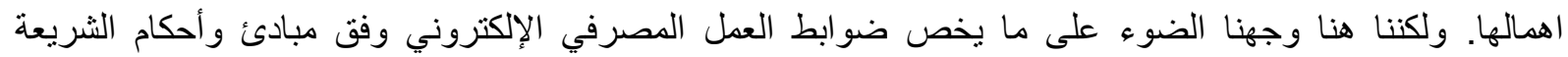
الإسلامية.

الخاتمة

إذا أدرك الإنسان المسلم أن الفهم الصحيح للإسلام عقبدة وفقهاً. قو اعد وضو ابط شرعية، و إيماناً صادقاً بان الالتزام بها الإنا

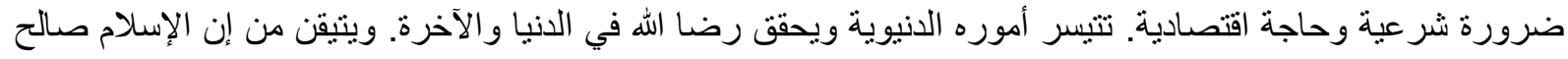

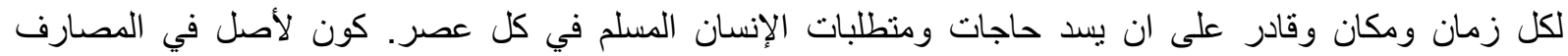

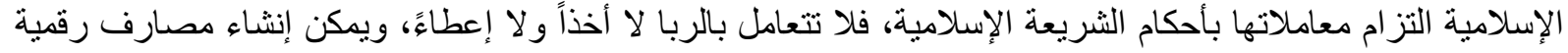

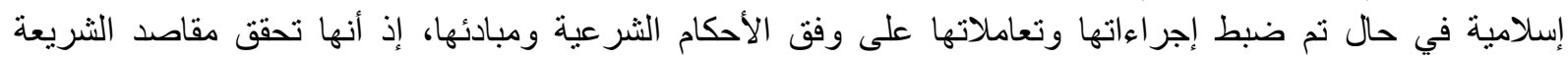

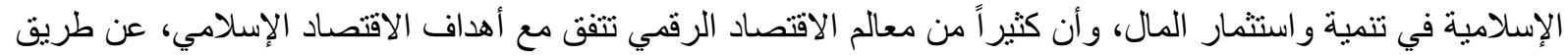

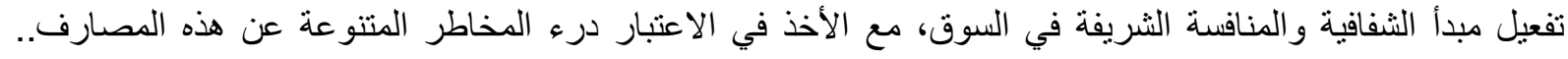

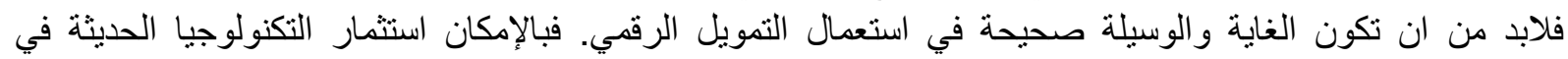
مصلحة الفرد و المجتمع و هو مقصد رئيس من مقاصد الثريعة الإسلامية...وقد توصلت في هذا البحث لنتائج أهمها: 
ـ أن الضوابط الثرعية تعد الدستور الإسلامي للمعاملات المالية المصرفية، لان الغاية منها بيان الحلال الذبي يجب

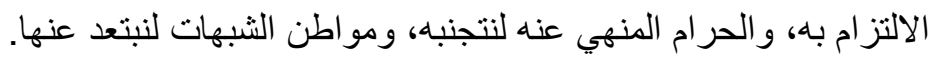

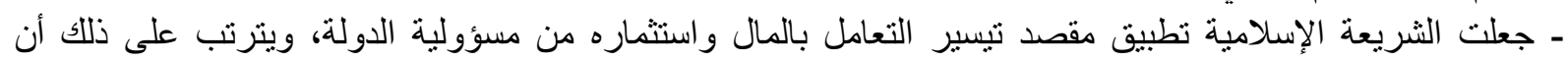

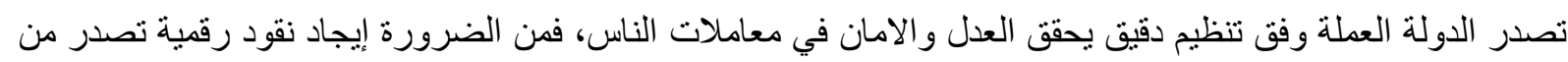

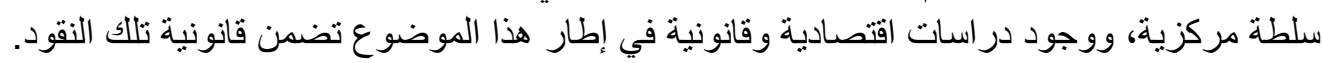

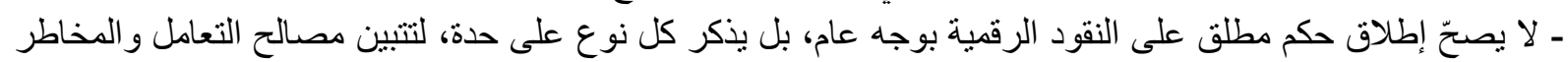
الاقتصادية المحفة بها. - يتطلب العمل في مجال الصيرفة الإلكترونية المعرفة الناضجة والقادرة على تطوير استر اتيجية شاملة وواضحة مقترنة بنطبيق دقيق لبر امجه لكي يتسنى للعمل المصرفي العنير تحقيق أهدافه المرجوة.

القران الكريم وبعده المصادر الآتية:

الإنصاف في معرفة الخلاف، المرداوي علاء الدين (885ه) دار إحياء التراث العربي الأصل في العقود الإباحة دراسة

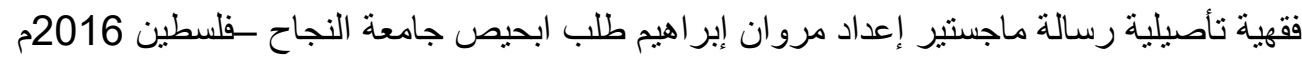

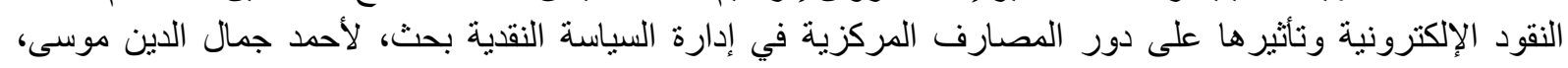

$$
\text { بيروت- منشور ات الحلبي }
$$

الآثار النقدية والاقتصادية و المالية للنقود الإكترونية، محمد إبر اهيم الثافعي، القاهرة-دار النهضة العربية العادية (2003م).

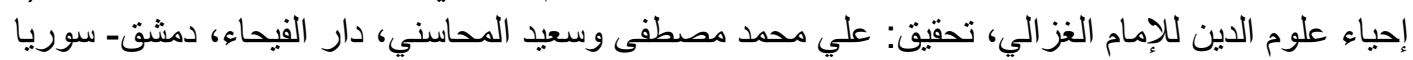

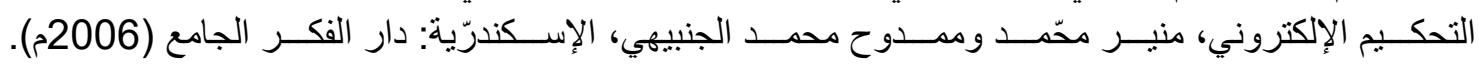

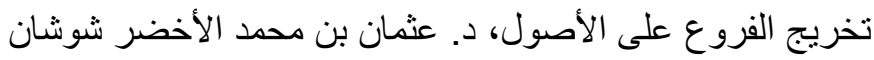

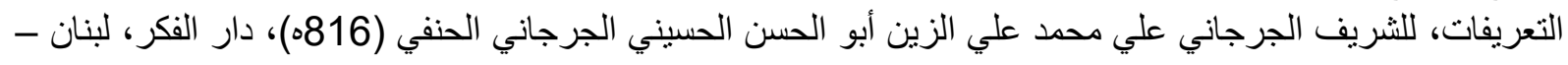
بيروت (1425-1426ه).

التكييف الفقهي للإعمال المصرفية الإلكترونية ـ مفهومه، أهميته، وضوابطه د. مسفر بن علي بن محمد القحطاني -

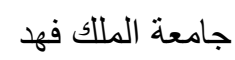

شرح الكواكب المنير المسمى بمختصر التحرير، محمد بن احمد بن عبد العزيز الفتوحي، تحقيق محمد الزحيلي سنزيه حماد

صحيح البخاري بهامش فتح الباري، ابو عبداله محمد بن إسماعيل بن إبراهيم البخاري (256ه)، طبع المطبعة الخيرية،

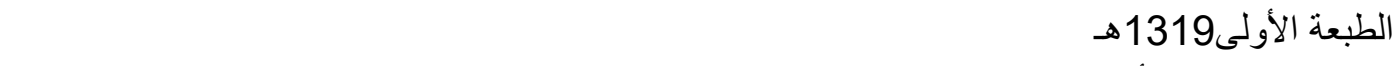

صحيح مسلم، مسلم بن الحجاج أبو الحسين القثيري النيسابوري (261ه)، تحقيق: محمد فؤاد عبد الباقي، المطبعة

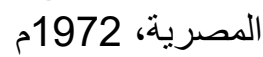

الضو ابط و القو اعد الثر عية للمعاملات المالية الإسلامية، د. إسماعيل خالدي.

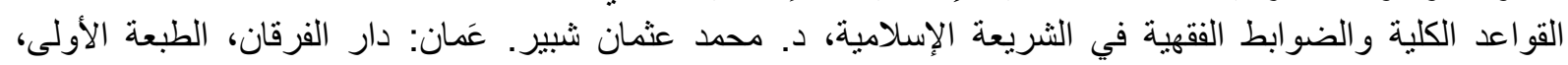

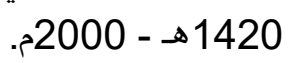

النقود الإلكترونبة حكمها الثر عي وآثار ها الاقتصادية، اطروحة دكتور اه، سارة ملتع القحطاني جامعة الكويت، 2008م

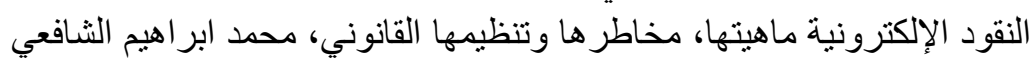
النقود الافتراضية مفهومها و أنو اعها و آثار ها الاقتصادية، المجلة العلمية للاقتصاد والتهانية التهارة، كلية التجارة، عبد الله بن

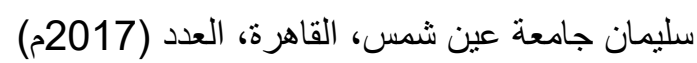

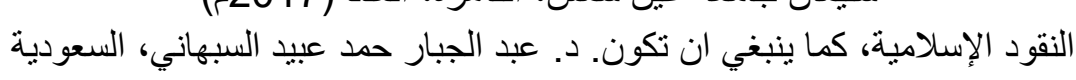

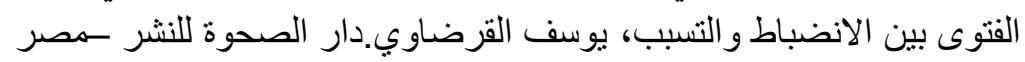

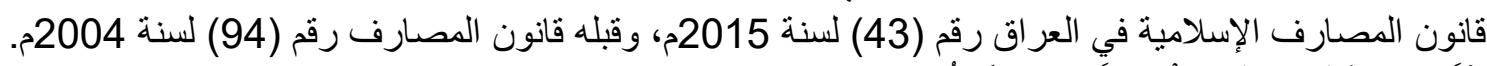

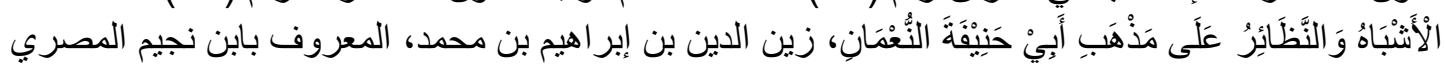

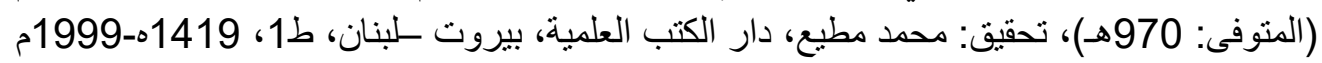
القو اعد الفقهية والضوا ابط الثر عية للمعاملات المالية المعاصرة، د.حسين حسين شحاتة، سلسلة ودراسات في في فقه رجال الاعمال

القو اعد و الضوابط الفقهية عند ابن تيمية، عبد السلام ابر اهيم بن محمد الحصين، القاهرة 2002م، 
القو اعد و الضوابط الققهية للمعاملات المالية عند ابن تيمية، عبد السلام ابر اهيم الحصين،

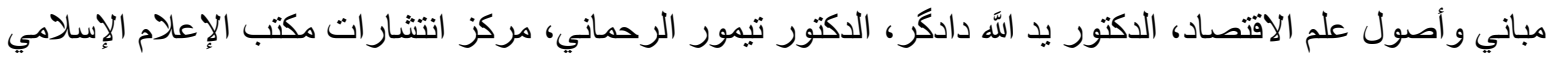

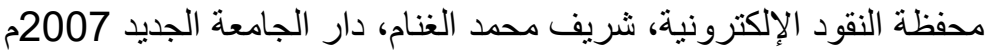

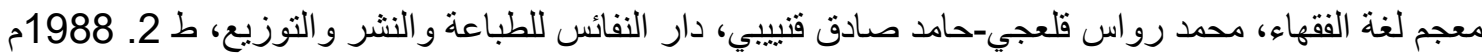

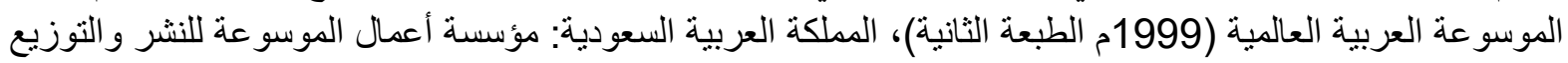

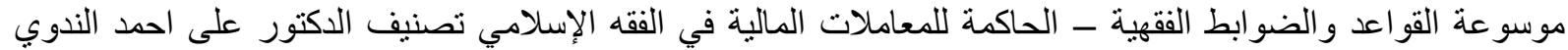
1999م

النقود الإلكترونبة وحكمها الثرعي وأثار ها الاقتصادية سارة متلع القحطاني (أطروحة دكتور اه)

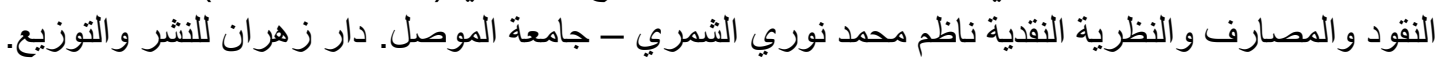

